\title{
Kepelbagaian dan Kelimpahan Foraminifera di Sedimen Permukaan Sekitar Delta Sungai Kelantan, Malaysia
}

(Diversity and Abundance of Foraminifera at Surface Sediment along Sungai Kelantan Delta, Malaysia)

\author{
NORASWANA NOR FAIZ*, KAMAL ROSLAN MOHAMED, RAMLAN OMAR \& ZULKHAIRI AKMAR AHMAD
}

\begin{abstract}
ABSTRAK
Suatu kajian telah dijalankan untuk menentukan kepelbagaian dan kelimpahan foraminifera di sedimen permukaan sekitar delta Sungai Kelantan memandangkan kajian foraminifera terutamanya di perairan marin Malaysia amat kurang. Sejumlah 22 stesen daripada dua garisan transek telah ditentukan sebagai kawasan persampelan. Sebanyak 10,317 individu foraminifera yang terdiri daripada 27 famili, 34 genus dan 55 spesies telah ditemui di kawasan kajian. Secara keseluruhannya, famili Hauerinidae mencatatkan kepelbagaian spesies tertinggi (10 spesies) manakala famili paling dominan dengan jumlah individu tertinggi ialah Rotaliidae (26.14\%). Spesies dominan dan paling melimpah di kawasan kajian ialah Asterorotalia pulchella (17.24\%) dan Operculina ammonoides (10.19\%).Indeks kepelbagaian spesies, $H^{\prime}$ yang dicatatkan ialah antara 0.5 hingga 3.1 manakala indeks kekayaan spesies, $\alpha$ adalah antara 1.5 hingga 7.9. Kelimpahan dan kepelbagaian spesies tertinggi $\left(\alpha=7.9, H^{\prime}=3.1\right)$ dicatatkan pada stesen 21 yang terletak di laut terbuka dengan kedalaman air sebanyak $36.8 \mathrm{~m}$ dan bersaliniti 32.2 ppt mendekati laut normal. Nilai H'dan $\alpha$ terendah dicatatkan pada stesen yang berdekatan dengan muara sungai yang cetek dan bersaliniti lebih rendah. Secara keseluruhannya, nilai indeks kepelbagaian yang dicatatkan di kawasan kajian adalah menepati persekitaran marin berair cetek. Kesimpulannya, kepelbagaian dan kelimpahan foraminifera di kawasan kajian dipengaruhi oleh kedalaman dan saliniti air.
\end{abstract}

Kata kunci: Delta Sungai Kelantan; foraminifera; kelimpahan; kepelbagaian

\section{ABSTRACT}

A study was conducted to determine the diversity and abundance of surface sediment foraminifera at the delta of Sungai Kelantan as information on foraminifera, especially in Malaysia marine waters, is scarce. A total of 22 stations from two transects were designated as sampling areas. A total of 10,317 individuals belonging to 27 families, 34 genera and 55 species of foraminifera were found in the study area. Family Hauerinidae, with 10 species recorded, had the highest species diversity while Rotaliidae was the family with most abundant individuals (26.14\%). The dominant and abundant species in the study area were Asterorotalia pulchella (17.24\%) and Operculina ammonoides (10.19\%). The species diversity index, $H^{\prime}$ and species richness index, $\alpha$ recorded were between 0.5 and 3.1 and 1.5 and 7.9 , respectively. The highest abundance and diversity of species $\left(\alpha=7.9, H^{\prime}=3.1\right)$ was recorded at station 21 as this station was located in open sea with a depth of $36.8 \mathrm{~m}$ and salinity at $32.2 \mathrm{ppt}$, close to normal marine salinity. The lowest $H^{\prime}$ and $\alpha$ values were recorded for stations near estuary with shallow waters and lower salinity. In general, the diversity index recorded at the delta of Sungai Kelantan belongs to the shallow water of marine environments. In conclusion, the diversity and abundance of foraminifera at the delta of Sungai Kelantan was influenced by the depth of its waters and salinity.

Keywords: Abundance; diversity; foraminifera; Sungai Kelantan delta

\section{PENGENALAN}

Foraminifera merupakan organisma yang wujud sejak zaman Kambria, iaitu lebih dari 525 juta tahun yang lalu (Pringgoprawiro \& Kapid 2000). Sehingga kini dianggarkan terdapat 60,000 fosil foraminifera dan spesies foraminifera moden yang telah dikenal pasti (Sen Gupta 2003). Secara umumnya, foraminiera adalah mikroorganisma bersel tunggal yang hidup secara akuatik, mempunyai satu atau lebih kebuk yang terpisah satu sama lain oleh septum yang ditembusi oleh banyak lubang halus (Pringgoprawiro \& Kapid 2000). Terdapat hampir 10,000 spesies foraminifera hidup pada masa kini yang majoritinya terdiri daripada jenis bentik iaitu daripada suborder
Allogromiina, Textulariina, Involutinina, Spirillinina, Miliolina, Lagenina, Robertinina dan Rotaliina, manakala hanya 40 hingga 50 spesies daripada jenis planktonik iaitu daripada suborder Globigerinina. Ini menjadikan mikroorganisma bercengkerang ini sangat melimpah taburannya di perairan moden (Sen Gupta 2003).

Berdasarkan pengelasan oleh Loeblich dan Tappan (1988), foraminifera tergolong dalam kingdom Protista, filum Sarcodina, kelas Rhizopoda dan order Foraminiferida. Dalam pengecaman dan pengelasan spesies foraminifera, pengamatan terhadap jenis dinding, bentuk cengkerang, bukaan dan hiasan perlu diteliti dengan baik. Haynes (1981) membahagikan komposisi dinding cengkerang 
kepada tiga kumpulan iaitu dinding berkitin, dinding aglutinat dan dinding berkapur. Cengkerang foraminifera terbentuk sama ada daripada sebatian organik, butiran pasir atau zarah lain yang tersimen bersama atau daripada $\mathrm{CaCO}_{3}$ kristal (kalsit atau aragonit). Ia terbahagi kepada bilik yang bertambah semasa pembesarannya atau dalam bentuk yang paling ringkas seperti sfera berongga atau tiub terbuka (Pawlowski 2009). Bentuk cengkerang biasanya terdiri daripada kebuk tunggal (unilocular) atau lebih kebuk (multilocular). Bukaan yang berbentuk seperti lubang adalah berfungsi untuk kemasukan makanan dan juga untuk mengeluarkan protoplasma, manakala hiasan pula adalah aneka struktur mikro yang menghiasi bentuk fizikal cengkerang foraminifera (Pringgoprawiro \& Kapid 2000).

Kajian foraminifera terdahulu di perairan Malaysia lebih tertumpu kepada persekitaran muara dan paya bakau yang merekodkan penemuan lebih daripada 100 spesies foraminifera (Abdul Razak \& Husain 2013; Culver et al. 2013, 2012; Dhillon 1969; Hawkes et al. 2007; Husain et al. 2007). Tidak banyak kajian foraminifera dijalankan di perairan marin Malaysia. Antara kajian yang menyumbang kepada maklumat taburan foraminifera di perairan marin Malaysia ialah Minhat et al. (2014), Noraswana et al. (2016) dan Yahya et al. (2014). Manakala kajian tentang fosil foraminifera telah dijalankan oleh Asis dan Jasin (2015) dan Whittaker dan Hodgkinson (1969). Maka, kajian bagi menentukan kepelbagaian dan kelimpahan foraminifera di delta Sungai Kelantan ini dijalankan bagi memenuhi kekurangan maklumat dan menambah data sedia ada tentang tentang mikrofauna di perairan marin Malaysia.

\section{BAHAN DAN KAEDAH}

\section{KAWASAN PENSAMPELAN}

Lokasi kajian ini di sekitar delta Sungai Kelantan (Rajah 1) yang terletak di pantai timur Semenanjung Malaysia. Kawasan ini terdedah kepada tindakan ombak yang kuat, terutamanya semasa musim tengkujuh (November hingga Februari) setiap tahun. Kawasan takungannya adalah seluas kira-kira $11,900 \mathrm{~km}^{2}$ dan mengalir ke arah Laut China Selatan. Delta Kelantan mempunyai muara berlumpur yang ditumbuhi oleh pokok bakau, dengan banyak alur pengedar kecil (Mohamed et al. 1997). Sebanyak 22 stesen daripada dua transek (11 stesen pada setiap transek) telah dipilih sebagai stesen persampelan. Persampelan dijalankan selama empat hari dan mengikut garisan transek bermula dari muara sungai hingga ke laut terbuka yang mempunyai jarak $3 \mathrm{~km}$ antara stesen. Gambaran kedudukan dan koordinat setiap stesen persampelan adalah seperti yang ditunjukkan dalam Rajah 1 dan Jadual 1.

\section{KAEDAH PERSAMPELAN}

Dalam penentuan koordinat stesen persampelan di delta Sungai Kelantan, alat Sistem Kedudukan Global (GPS) model Garmin telah digunakan. Alat kedalaman meter digunakan bagi mengukur kedalaman air setiap stesen persampelan. Manakala, alat sistem paparan pelbagai

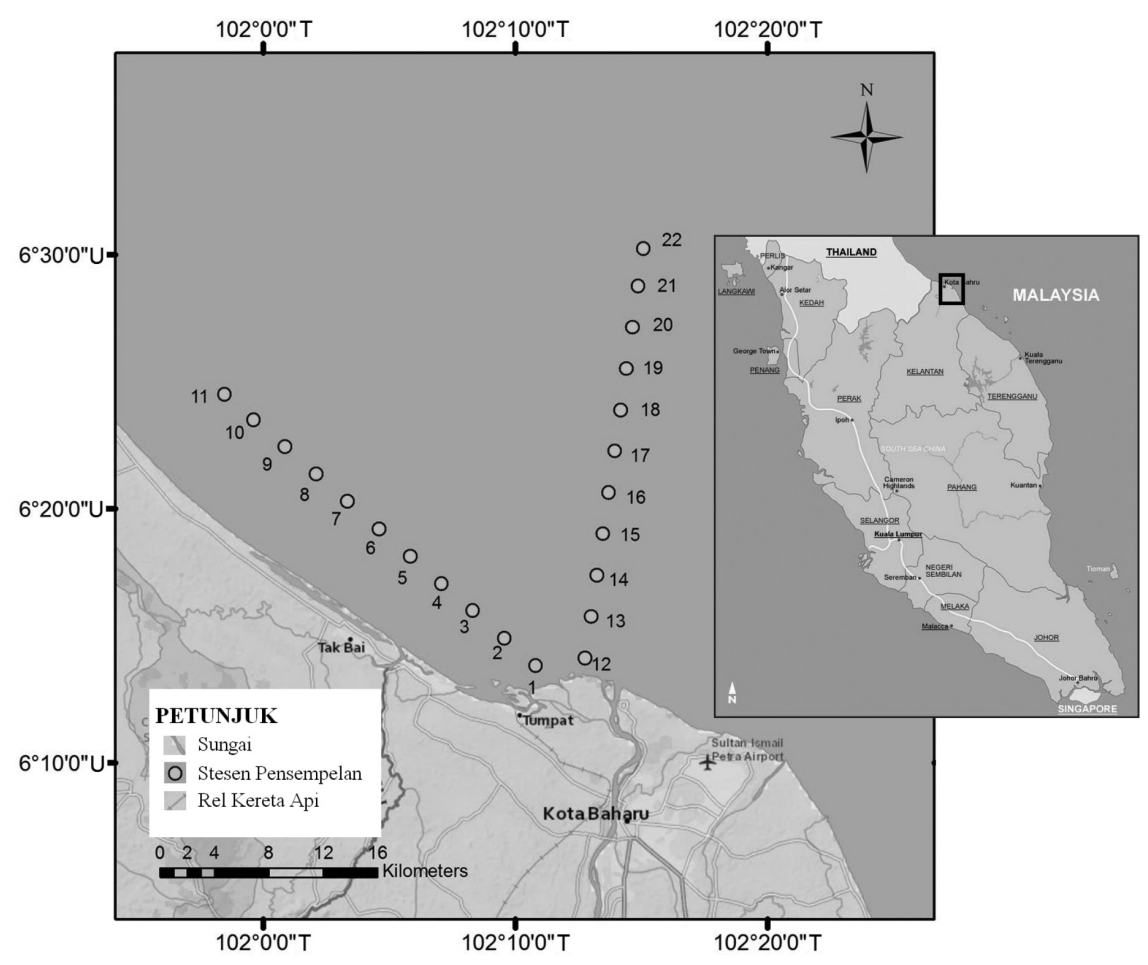

RAJAH 1. Lokasi stesen persampelan di delta Sungai Kelantan, Malaysia 
parameter (YSI 556) digunakan untuk mengambil bacaan saliniti air di tempat kajian. Pengambilan sampel dijalankan dengan menggunakan alat pensampel cekau (isi padu: 2.4 L; kawasan sampel: $152 \times 152 \mathrm{~mm}$; berat: $14 \mathrm{~kg}$ ) untuk mencakup sedimen di bahagian dasar. Sedimen yang berjaya dicakup dimasukkan ke dalam beg plastik dan dilabelkan.

\section{KAEDAH MAKMAL}

Sampel sedimen yang telah diambil kemudiannya diproses menggunakan kaedah ayak basah dengan siri ayak 'Retsch' bersaiz mesh $2 \mathrm{~mm}, 500 \mu \mathrm{m}, 150 \mu \mathrm{m}$ dan $63 \mu \mathrm{m}$ dengan bantuan aliran air paip sederhana kuat sehingga bersih. Sampah sarap yang terperangkap pada penapis ayak (saiz jaringan $2 \times 2 \mathrm{~mm}$ ) dibuangkan dan selebihnya dikeringkan dalam ketuhar pada suhu $50^{\circ} \mathrm{C}$ hingga $70^{\circ} \mathrm{C}$. Setelah kering, 3 g subsampel ini dimasukkan ke dalam botol penyimpanan serta dilabelkan. Hasil ayakan ditaburkan di atas sekeping kad hitam tebal yang mempunyai petak-petak kecil berukuran $1 \mathrm{~cm}^{2}$. Sampel diteliti dan dikenal pasti di bawah mikroskop pantulan cahaya (Olympus SZ61) di bawah kuasa pembesaran $40 \times$ untuk mengasingkan spesies foraminifera daripada butiran sampel. Spesimen yang dikenal pasti diambil dengan menggunakan berus kecil dan disimpan dalam slaid mikropaleontologi. Pengiraan spesimen yang diperoleh turut dilakukan semasa kerja pengasingan dijalankan.

\section{PENGELASAN FORAMINIFERA}

Pengecaman spesimen foraminifera ke peringkat famili dijalankan melalui mikroskop pantulan cahaya manakala bagi peringkat genus dan spesies pula ditentukan melalui mikroskop elektron imbasan (Hitachi TM-1000) di Pusat Pengajian Sains Sekitaran dan Sumber Alam, Fakulti Sains dan Teknologi, Universiti Kebangsaan Malaysia. Perbandingan ciri morfologi spesies untuk pengecaman spesies adalah berdasarkan monograf taksonomi oleh Jones (1994), Loeblich dan Tappan (1988), Milker dan Schmiedl (2012) dan Whittaker dan Hodgkinson (1969).

\section{ANALISIS DATA}

Kepelbagaian spesies ditentukan dengan menggunakan indeks kepelbagaian Shannon-Wiener (Shannon \& Weaver 1949). Indeks Fisher-Alpha digunakan dalam kajian ini untuk menilai tahap kekayaan spesies (Fisher et al. 1943). Analisis korelasi Pearson digunakan untuk mengkaji hubungan antara kepelbagaian dan kelimpahan foraminifera dengan kedalaman air di kawasan kajian. Analisis data dilakukan dengan menggunakan perisian statistik PAST (Paleontological Statistic). Di dalam kajian ini, terma 'melimpah' digunakan pada sesuatu spesies yang menunjukkan peratusan lebih daripada $10 \%$ daripada jumlah spesimen yang ditemui, manakala 'biasa' merujuk kepada spesies dengan julat 5 hingga $10 \%$ dan 'jarang' bagi spesies yang kurang daripada 5\% (Whatley \& Zhao 1987).

\section{KEPUTUSAN DAN PERBINCANGAN}

\section{PARAMETER KEDALAMAN DAN SALINITI}

Bacaan nilai kedalaman air serta saliniti air pada stesen persampelan di delta Sungai Kelantan ditunjukkan dalam Jadual 1. Julat kedalaman air di kawasan kajian adalah 6.3-39.0 m dengan purata kedalaman 21.9 \pm 10.2 $\mathrm{m}$. Kedalaman air yang dicatatkan semakin meningkat dari muara ke laut terbuka. Saliniti air yang dicatatkan berada dalam lingkungan marin normal iaitu 30-39 ppt (Murray 1991) kecuali pada Stesen 1 dan 12 yang mencatatkan bacaan <30 ppt (Jadual 1). Ini menunjukkan adanya percampuran air tawar daripada Sungai Kelantan memandangkan ia terletak berdekatan dengan muara sungai. Menurut Liu et al. (2001), antara perubahan yang dibawa oleh kemasukan air tawar, perubahan saliniti adalah yang paling ketara. Bacaan purata bagi saliniti air di kawasan kajian ialah $31.8 \pm 0.7$ ppt.

\section{KELIMPAHAN FORAMINIFERA BENTIK}

Daripada kajian yang dijalankan, sebanyak 10,317 individu foraminifera telah ditemui di tempat kajian dengan bilangan individu tertinggi dicatatkan pada stesen 20 (1,639 individu; $15.89 \%$ ) (Rajah 2). Kelimpahan dan kepelbagaian spesies foraminifera tertinggi $\left(H^{\prime}=3.1, \alpha=7.9\right)$ adalah dicatatkan pada stesen 21 selama empat hari tempoh penyampelan (Rajah 2). Manakala, kelimpahan dan kepelbagaian spesies foraminifera terendah $\left(\mathrm{H}^{\prime}=0.5, \alpha=1.5\right.$ ) pula adalah dicatatkan pada stesen 2 (Rajah 2). Ini jelas menunjukkan kelimpahan dan kepelbagaian foraminifera mencatatkan bilangan yang lebih tinggi di stesen dengan kedudukannya terletak pada laut terbuka dengan kedalaman yang lebih dalam (>35 m) dan bersaliniti laut normal.

Sebanyak 27 famili, 34 genus dan 55 spesies telah berjaya ditemui di kesemua 22 stesen persampelan sekitar delta Sungai Kelantan. Daripada famili yang ditemui, Rotaliidae merupakan famili yang dominan dengan 2,697 individu (26.14\%) diikuti Hauerinidae dengan 1,662 individu (16.11\%). Globigerinidae daripada kumpulan planktonik mencatatkan jumlah individu paling rendah iaitu hanya dua individu sahaja. Famili Hauerinidae mencatatkan kepelbagaian spesies tertinggi iaitu sebanyak 10 spesies berjaya dijumpai dan diikuti oleh Textularidae dengan 8 spesies (Jadual 2).

Nilai kepelbagaian yang dicatatkan di kawasan kajian adalah sederhana dan menepati persekitaran marin normal iaitu saliniti air laut antara 30-39 ppt. Menurut Murray (2006), kesemua persekitaran marin pinggiran dan pelantar laut air payau mempunyai kepelbagaian yang rendah manakala persekitaran marin normal dan lagun hipersaliniti mencatatkan nilai diversiti yang sederhana. Nilai diversiti yang tinggi dengan nilai $\alpha$ antara 10-30 dan nilai H' antara 2.0->4.0 dicatatkan pada kawasan laut dalam dan pelantar laut (Murray 2006). Menurut Mendes et al. (2004), jika nilai $H^{\prime}$ antara 0 dan 2 dinyatakan sebagai mempunyai kepelbagaian rendah, 2-4 kepelbagaian sederhana dan $>4$ 
JADUAL 1. Koordinat, kedalaman dan saliniti bagi setiap stesen penyampelan bagi kajian foraminifera pada sedimen permukaan di delta Sungai Kelantan

\begin{tabular}{|c|c|c|c|c|}
\hline Stesen & Latitud (U) & Longitud (T) & Kedalaman (m) & Saliniti (ppt) \\
\hline 1 & $6^{\circ} 13^{\prime} 50^{\prime \prime}$ & $102^{\circ} 10^{\prime} 49^{\prime \prime}$ & 7.3 & 29.7 \\
\hline 2 & $6^{\circ} 14^{\prime} 54^{\prime \prime}$ & $102^{\circ} 09^{\prime} 34^{\prime \prime}$ & 9.4 & 30.9 \\
\hline 3 & $6^{\circ} 15^{\prime} 60^{\prime \prime}$ & $102^{\circ} 08^{\prime} 19^{\prime \prime}$ & 11.4 & 31.3 \\
\hline 4 & $6^{\circ} 17^{\prime} 04^{\prime \prime}$ & $102^{\circ} 07^{\prime} 05 "$ & 11.8 & 31.9 \\
\hline 5 & $6^{\circ} 18^{\prime} 08^{\prime \prime}$ & $102^{\circ} 05^{\prime} 50^{\prime \prime}$ & 14.5 & 32.0 \\
\hline 6 & $6^{\circ} 19^{\prime} 12^{\prime \prime}$ & $102^{\circ} 04^{\prime} 36^{\prime \prime}$ & 16.3 & 32.1 \\
\hline 7 & $6^{\circ} 20^{\prime} 18^{\prime \prime}$ & $102^{\circ} 03 ' 20 "$ & 18.8 & 32.0 \\
\hline 8 & $6^{\circ} 21^{\prime} 22^{\prime \prime}$ & $102^{\circ} 02^{\prime} 06^{\prime \prime}$ & 20.2 & 32.0 \\
\hline 9 & $6^{\circ} 22^{\prime} 27^{\prime \prime}$ & $102^{\circ} 00^{\prime} 52^{\prime \prime}$ & 21.2 & 32.0 \\
\hline 10 & $6^{\circ} 23^{\prime} 31^{\prime \prime}$ & $101^{\circ} 59^{\prime} 38^{\prime \prime}$ & 20.0 & 32.1 \\
\hline 11 & $6^{\circ} 24^{\prime} 31^{\prime \prime}$ & $101^{\circ} 58^{\prime} 28^{\prime \prime}$ & 20.2 & 32.1 \\
\hline 12 & $6^{\circ} 14^{\prime} 07^{\prime \prime}$ & $102^{\circ} 12^{\prime} 46^{\prime \prime}$ & 6.3 & 29.8 \\
\hline 13 & $6^{\circ} 15^{\prime} 45^{\prime \prime}$ & $102^{\circ} 12^{\prime} 60^{\prime \prime}$ & 14.5 & 31.9 \\
\hline 14 & $6^{\circ} 17^{\prime} 23^{\prime \prime}$ & $102^{\circ} 13^{\prime} 14^{\prime \prime}$ & 22.4 & 32.0 \\
\hline 15 & $6^{\circ} 19^{\prime} 01^{\prime \prime}$ & $102^{\circ} 13^{\prime} 28^{\prime \prime}$ & 24.2 & 32.0 \\
\hline 16 & $6^{\circ} 20^{\prime} 38^{\prime \prime}$ & $102^{\circ} 13^{\prime} 42^{\prime \prime}$ & 25.8 & 32.1 \\
\hline 17 & $6^{\circ} 22^{\prime} 16^{\prime \prime}$ & $102^{\circ} 13^{\prime} 56^{\prime \prime}$ & 33.8 & 32.3 \\
\hline 18 & $6^{\circ} 23^{\prime} 54^{\prime \prime}$ & $102^{\circ} 14^{\prime} 10^{\prime \prime}$ & 34.8 & 32.2 \\
\hline 19 & $6^{\circ} 25^{\prime} 30^{\prime \prime}$ & $102^{\circ} 14^{\prime} 24^{\prime \prime}$ & 35.4 & 32.1 \\
\hline 20 & $6^{\circ} 27^{\prime} 08^{\prime \prime}$ & $102^{\circ} 14^{\prime} 38^{\prime \prime}$ & 35.6 & 32.1 \\
\hline 21 & $6^{\circ} 28^{\prime} 46^{\prime \prime}$ & $102^{\circ} 14^{\prime} 52^{\prime \prime}$ & 36.8 & 32.2 \\
\hline 22 & $6^{\circ} 30^{\prime} 15^{\prime \prime}$ & $102^{\circ} 15^{\prime} 05^{\prime \prime}$ & 39.0 & 32.2 \\
\hline
\end{tabular}
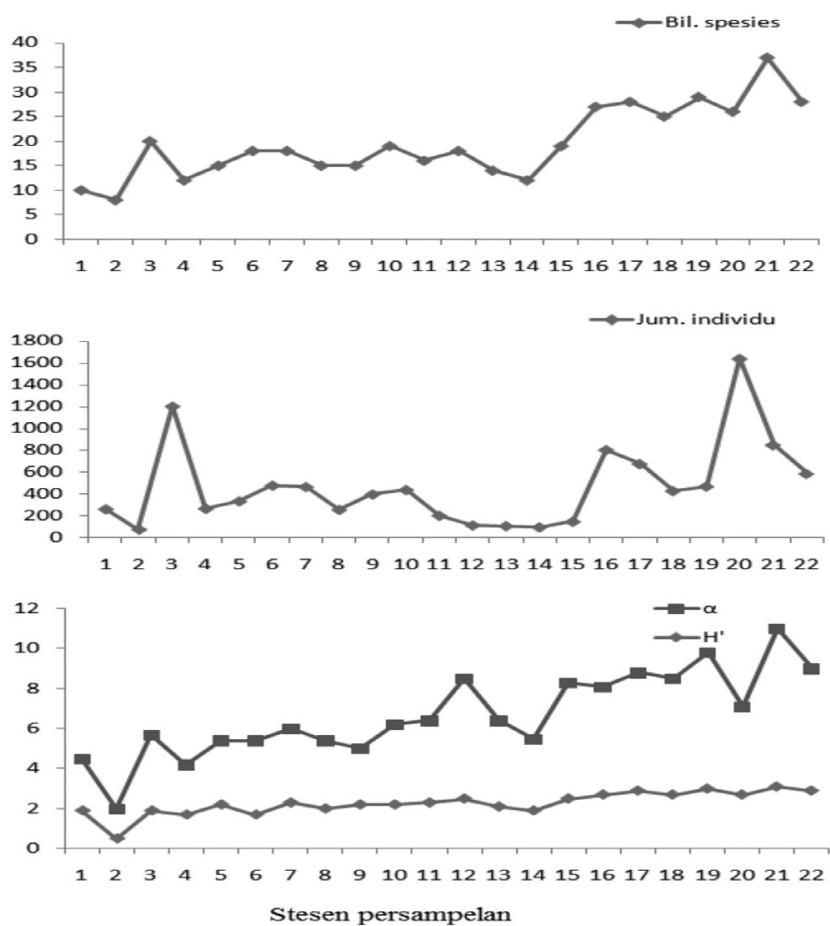

RAJAH 2. Bilangan spesies, jumlah individu, indeks kepelbagaian Shannon-Wiener (H') dan indeks kekayaan Fisher-Alpha $(\alpha)$ mengikut stesen persampelan di delta Sungai Kelantan selama empat hari tempoh persampelan

sebagai kepelbagaian tinggi. Semakin besar nilai indeks H', maka kelimpahan relatif dan kepelbagaian spesies akan semakin besar.
Graf Indeks $\alpha$ oleh Wright biasanya digunakan untuk menerangkan perkaitan dengan persekitaran foraminifera (Valchev 2003). Nilai Indeks $\alpha$ yang 
dicatatkan menunjukkan persekitaran di kawasan kajian dikategorikan di dalam kawasan lautan pelantar benua bersaliniti normal. Indeks $\alpha$ juga turut digunakan dalam menentukan perkaitan dengan batimetri. Menurutnya, apabila kedalaman meningkat, nilai indeks $\alpha$ juga bertambah. Nilai indeks $\alpha$ dan H' yang paling tinggi di kawasan kajian dicatatkan pada kedalaman 36.8 m. Keputusan analisis statistik menunjukkan terdapat hubungan yang signifikan antara nilai indeks $\alpha(r=0.806$, $p<0.05)$ dan H' $(r=0.833, p<0.05)$ (Ujian Korelasi Pearson) dengan kedalaman air (Rajah 3). Ini bererti nilai indeks $\alpha$ dan H' meningkat dengan bertambahnya kedalaman air. Menurut Szarek et al. (2006), kedalaman menjadi salah satu faktor yang penting dalam mengawal taburan foraminifera bentik dalam kebanyakan kajian. Kestabilan persekitaran biasanya meningkat dengan peningkatan kedalaman menjadikannya lebih sesuai didiami oleh habitat foraminifera.

Nilai indeks kepelbagaian yang dicatatkan di kawasan kajian juga mungkin mempunyai kaitan dengan pengaruh kemasukan air tawar daripada Sungai Kelantan. Ini dapat dilihat kerana stesen berdekatan muara sungai (Stesen 1 dan 12) dengan bacaan saliniti lebih rendah (<30 ppt) mencatatkan kelimpahan dan kepelbagaian spesies yang lebih rendah. Nilai H' yang lebih tinggi juga direkodkan pada stesen yang terletak jauh dari muara sungai. Muara sungai, pelepasan air tawar dari sungai bersama dengan faktor lain seperti arus pasang surut dan ombak mungkin menjadi faktor pengehad kepada kepelbagaian spesies foraminifera di stesen yang terletak berdekatan dengan mulut sungai. Di kawasan pantai, percampuran air tawar adalah ketara mengubah ciri air dan dengan itu memberi kesan kepada himpunan foraminifera (Murray 1991; Murray \& Alve 1999). Daripada beberapa faktor biologi dan fiziko-kimia yang mempengaruhi taburan foraminifera di kawasan marin pingggiran, larian air tawar yang berkait dengan perubahan saliniti adalah paling menonjol terutamanya di kawasan air cetek (Annin 2001; Frezza \& Carboni 2009; Mendes et al. 2004).

Daripada 55 spesies yang telah berjaya dikenal pasti, hanya dua spesies sahaja dikategorikan sebagai melimpah, iaitu Asterorotalia pulchella dan Operculina ammonoides. Manakala hanya satu spesies iaitu Amphistegina lessonii dikategorikan sebagai biasa (Jadual 2). Sebanyak 20 spesies 'jarang' yang menunjukkan aras populasi 1 hingga 5\% dan 32 spesies selebihnya menunjukkan aras populasi kurang daripada 1\% di tempat kajian (Jadual 2). Asterorotalia pulchella merupakan spesies paling dominan di kawasan kajian iaitu sebanyak 1,779 individu (17.24\%), diikuti oleh $O$. ammonoides $(10.19 \%)$ dan A. lessonii $(6.15 \%)$ manakala spesies yang paling sedikit dijumpai ialah Globogerina sp. iaitu sebanyak dua individu sahaja (Jadual 2). Spesies ini (A. pulchella, O. ammonoides dan A. lessonii) merupakan antara spesies yang dominan dan biasa dijumpai di perairan Laut China Selatan yang dijumpai pada kedalaman $<60 \mathrm{~m}$ (Szarek et al. 2006).

Spesies A. lessonii dan $O$. ammonoides merupakan spesies foraminifera besar yang bersimbosis dengan alga simbion, epifaunal pada sedimen, mendiami perairan pada keadaan tenaga rendah dan keamatan cahaya yang sederhana (Murray 2006). Spesies A. lessonii mencatatkan kelimpahan yang tinggi sekitar perairan Pentas Vietnam (Szarek et al.2006) dan juga kawasan perairan Indo-Pasifik (Renema et al. 2001). Menurut Murray (2006), spesies $O$. ammonoides banyak ditemui pada kedalaman antara 20$70 \mathrm{~m}$ dan juga boleh bertoleransi dalam keadaan eutrofik. Namun begitu, Renema et al. (2001) menemukan banyak spesies $O$. ammonoides di kawasan terumbu karang pada kedalaman 9 hingga 20 m sekitar perairan Indo-Pasifik. Spesies A. lessonii dan $O$. ammonoides pernah juga dilaporkan di Lautan India. Manakala, spesies A. pulchella pula merupakan spesies epifaunal di kawasan marin subtropika ke tropika dan antara spesies yang dominan yang direkodkan di Pentas Sunda (Szarek et al. 2006). Selain itu, spesies A. pulchella juga turut direkodkan di Formasi Togopi, Sabah (Whittaker \& Hodgkinson 1979), Indonesia (Troelstra et al. 1996) dan Lautan Pasifik (Jones 1994). Ketiga-tiga spesies dominan ini turut direkodkan di muara dan lagun Setiu, Terengganu (Culver et al. 2012).

Corak taburan umum dalam komposisi fauna bagi kelimpahan foraminifera bentik adalah berdasarkan perkadaran daripada order yang utama. Himpunan
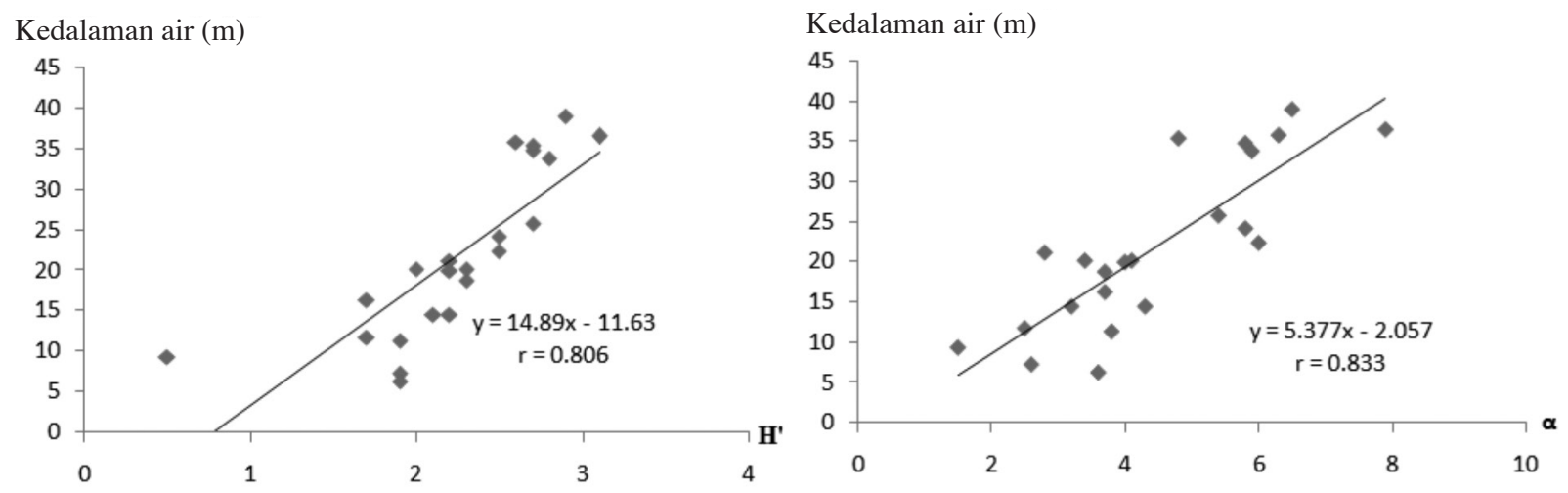

RAJAH 3. Hubungan korelasi antara kedalaman air (m) dengan nilai indeks H' dan indeks $\alpha$ pada stesen persampelan di delta Sungai Kelantan (Ujian korelasi Pearson) 
JADUAL 2. Bilangan individu dan peratus kelimpahan bagi setiap spesies yang dijumpai di 22 stesen penyampelan sekitar delta Sungai Kelantan

\begin{tabular}{|c|c|c|c|c|}
\hline Order & Famili & Spesies & Jumlah & $\%$ kelimpahan \\
\hline \multirow{3}{*}{ Lituolida } & Lituolidae & Ammobaculites agglutinans & 289 & 2.80 \\
\hline & & Ammobaculites filiformis & 34 & 0.33 \\
\hline & Reophacidae & Reophax scorpiurus & 49 & 0.47 \\
\hline \multirow[t]{8}{*}{ Textulariida } & Textulariidae & Bigenerina nodosaria & 90 & 0.87 \\
\hline & & Bigenerina sp. & 65 & 0.63 \\
\hline & & Sahulia conica & 195 & 1.89 \\
\hline & & Textularia agglutinans & 157 & 1.52 \\
\hline & & Textularia aciculata & 122 & 1.18 \\
\hline & & Textularia cushmani & 89 & 0.86 \\
\hline & & Textularia pseudogramen & 94 & 0.91 \\
\hline & & Textularia sp. & 20 & 0.19 \\
\hline \multirow[t]{4}{*}{ Buliminida } & Bolivinitidae & Bolivina sp. & 18 & 0.17 \\
\hline & & Brizalina striatula & 60 & 0.58 \\
\hline & & Pseudobrizalina lobata & 8 & 0.08 \\
\hline & Reussellidae & Reussella spinulosa & 55 & 0.53 \\
\hline \multirow[t]{23}{*}{ Rotaliida } & Amphisteginidae & Amphistegina lessonii & 635 & 6.15 \\
\hline & Anomalinidae & Anomalina pacoraensis & 52 & 0.50 \\
\hline & Cancrisidae & Cancris inflatus & 186 & 1.80 \\
\hline & Cibicididae & Cibicides dutemplei & 92 & 0.89 \\
\hline & & Lobatula lobatula & 350 & 3.39 \\
\hline & Discorbinellidae & Discorbinella sp. & 99 & 0.96 \\
\hline & Elphidiidae & Elphidium advenum & 372 & 3.61 \\
\hline & & Elphidium crispum & 209 & 2.03 \\
\hline & & Elphidium hispidulum & 237 & 2.30 \\
\hline & & Elphidium biperforatus & 47 & 0.46 \\
\hline & & Elphidium sp. & 12 & 0.12 \\
\hline & Globigerinidae & Globigerina sp. & 2 & 0.02 \\
\hline & Nonionidae & Nonion fabum & 254 & 2.46 \\
\hline & Nummulitidae & Operculina ammonoides & 1051 & 10.19 \\
\hline & Planorbulinidae & Planorbulinella larvata & 48 & 0.47 \\
\hline & Rosalinidae & Neoconorbina terqeumi & 116 & 1.12 \\
\hline & Rotaliidae & Ammonia tepida & 100 & 0.97 \\
\hline & & Asterorotalia pulchella & 1779 & 17.24 \\
\hline & & Cavarotalia annectens & 453 & 4.39 \\
\hline & & Pseudorotalia schroeteriana & 365 & 3.54 \\
\hline & Siphogenerinoididae & Allassoida virgula & 70 & 0.68 \\
\hline & & Siphogenerina raphana & 98 & 0.95 \\
\hline & Siphoninidae & Siphonina sp. & 50 & 0.48 \\
\hline \multirow[t]{16}{*}{ Miliolida } & Cribrolinoididae & Adelosina sp. & 101 & 0.98 \\
\hline & Hauerinidae & Ammomassilina alveoliniformis & 12 & 0.12 \\
\hline & & Miliolinella australis & 302 & 2.93 \\
\hline & & Pseudohauerina sp. & 27 & 0.26 \\
\hline & & Pyrgo millettii & 52 & 0.50 \\
\hline & & Quinqueloculina parkeri & 58 & 0.56 \\
\hline & & Quinqueloculina agglutinans & 204 & 1.98 \\
\hline & & Quinqueloculina reticulata & 289 & 2.80 \\
\hline & & Quinqueloculina philippinensis & 69 & 0.67 \\
\hline & & Quinqueloculina laevigata & 237 & 2.30 \\
\hline & & Triloculina tricarinata & 412 & 3.99 \\
\hline & Nubeculariidae & Nubeculina sp. & 41 & 0.40 \\
\hline & Ophthalmidiidae & Edentostomina cultrata & 43 & 0.42 \\
\hline & & Edentostomina sp. & 61 & 0.59 \\
\hline & Peneroplidae & Peneroplis pertusus & 159 & 1.54 \\
\hline & Spiroloculinidae & Spiroloculina communis & 190 & 1.84 \\
\hline \multirow[t]{2}{*}{ Lagenida } & Ellipsolagenidae & Oolina globosa & 26 & 0.25 \\
\hline & Lagenidae & Lagena striata & 12 & 0.12 \\
\hline
\end{tabular}


foraminifera di kawasan kajian adalah didominasi oleh order Miliolida dan Rotaliida. Ini merupakan komposisi yang biasa dijumpai dalam persekitaran marin normal (Murray 1991). Szarek et al. (2006) turut mencatatkan dominasi order Miliolida dan Rotaliida dalam kajiannya mengenai taburan foraminifera bentik di Pentas Sunda, Laut China Selatan. Spesies foraminifera di kawasan kajian mempunyai hampir 50\% persamaan dengan Pentas Sunda, Laut China Selatan. Antara spesies yang paling melimpah dan biasa dijumpai di kedua-dua kawasan ini ialah A. pulchella, O. ammonoides, Elphidium advenum, Pseudorotalia schroeteriana, Cavarotalia annectens dan Lobatula lobatula. Persamaan yang besar dalam kehadiran spesies mungkin disebabkan oleh delta Sungai Kelantan yang juga terletak dalam perairan Laut China Selatan. Kedalaman bagi kawasan neritik dalam di Pentas Sunda adalah antara 47 dan $100 \mathrm{~m}$.

Taksonomi sistematik bagi tiga spesies dominan dan melimpah (aras populasi $>5 \%$ ) dibincangkan seterusnya. Gambarajah bagi spesies foraminifera yang ditemui di delta Sungai Kelantan ditunjukkan dalam Plat 1 dan Plat 2.

\section{TAKSONOMI}

Filum FORAMINIFERA d'Orbigny, 1826

Order ROTALIIDA Lankester, 1855

Superfamili ASTERIGERINOIDEA d'Orbigny, 1839

Famili AMPHISTEGINIDAE Cushman, 1927

Genus Amphistegina d'Orbigny, 1826

Amphistegina lessonii d'Orbigny, 1826

Pl. 1, rjh. 11

1826 Amphistegina lessonii d'Orbigny: ms.304,pl. 17, rjh. 1-4.

1971 Amphistegina lessonii d'Orbigny; Bock, ms. 58, pl. 21, rjh. 10

1994 Amphistegina gibbosa d'Orbigny; Loeblich dan Tappan, ms. 156, 157, pl. 340, rjh. 1-9

2001 Amphistegina lessonii d'Orbigny; Renema et al., ms. 131, rjh. $10 \mathrm{f}$

2003 Amphistegina lessonii d'Orbigny; Javaux dan Scott, ms. 11, rjh 2.4-2.6

2013 Amphistegina lessonii d'Orbigny; Mohamed et al. ms. 295, pl. 2, rjh. 21

2015 Amphistegina lessonii d'Orbigny; Hanagata dan Nokbuhara, ms. 105, rjh. 31.5, 31.6

Morfologi: Dinding berkapur dan berliang halus. Cengkerang adalah trokospira, menginvolusi, lebar dan rata. Bahagian umbilikus lebih tebal daripada bahagian lingkar. Dorsal septumadalah berjejari, berlekuk terbalik di antara 2/3 jejari cengkerang. Ventral septum berbentuk sinus. Bukaan marginal dalaman dengan belahan kecil dan disempadani oleh bibir. Permukaan adalah licin dengan corak septum yang jelas.

Superfamili NUMMULITOIDEA de Blainville, 1827

Famili NUMMULITIDAE de Blainville, 1827

Genus Operculina d'Orbigny, 1826

Operculina ammonoides (Gronovius, 1781)

Pl. 1, rjh. 22

1781 Nautilus ammonoides Gronovius: ms.282, pl. 19, rjh. 5-6

1941 Operculina ammonoides (Gronovius); LeRoy, ms. 78, pl. 6, rjh. 24-25

1979 Operculina ammonoides (Gronovius); Whittaker dan Hodgkinson, ms. 92, pl. 9, rjh. 1-5

1991 Operculina ammonoides (Gronovius); Van Marle, ms. 196, pl. 21, rjh. 3

1994 Assilina ammonoides (Gronovius); Loeblich dan Tappan, ms. 682, pl. 804, rjh. 1-7

2001 Operculina ammonoides (Gronovius); Renema et al. ms. 141, rjh. 20b, 20c

Morfologi: Cengkerang adalah besar, bulat pada pandangan umbilikus. Pusaran separa menginvolusi ke evolut, planispiral pada lingkaran akhir. Pertengahan cengkerang dihiasi oleh pustul.

Superfamili ROTALIOIDEA Ehrenberg, 1839

Famili ROTALIIDAE Ehrenberg, 1839

Genus Asterorotalia Hofker, 1950

Asterorotalia pulchella (d'Orbigny, 1839)

Pl. 1, rjh. 26

1839 Calcarina pulchella d'Orbigny: ms. 80, pl.5, rjh. 16-18

1844 Rotalia pulchella (d'Orbigny); Brady, ms. 710, pl. 115 , rjh. 18

1987 Asterorotalia pulchella (d'Orbigny); Loeblich dan Tappan, ms. 665, pl. 769, rjh. 5-11

1994 Asterorotalia pulchella (d'Orbigny); Jones, ms. 114 ,pl. 115 , rjh. 8

2001 Asterorotalia pulchella (d'Orbigny); Szarek, ms. 226, pl. 27, rjh. 11, 12 
2012 Asterorotalia pulchella (d'Orbigny); Culver et al. ms. 114, rjh. 3(2)

2015 Asterorotalia pulchella (d'Orbigny); Hanagata dan Nokbuhara, ms. 120, rjh. 35.9, 35.10

Morfologi: Dinding adalah berkapur dan berliang. Cengkerang adalah rata dan trokospira ke hampir planispiral dan mempunyai lapan ke 12 kebuk pada lingkaran akhir. Kebuk pada bahagian umbilikus dipisahkan oleh sutur. Sutur adalah menekan. Bukaan membujur dan disusun secara menegak dan hampir sama. Permukaan adalah licin di antara bonjol, pustul dan permatang yang banyak. Tiga duri yang besar dapat dilihat di setiap penjuru cengkerang.

\section{KESIMPULAN}

Keputusan kajian menunjukkan kawasan sekitar delta Sungai Kelantan mempunyai kelimpahan dan kepelbagaian spesies foraminifera bentik yang tinggi. Foraminifera di kawasan persampelan telah dikategorikan kepada 24 famili, 34 genus dan 55 spesies daripada 10,317 individu foraminifera yang telah berjaya dicatatkan. Nilai indeks kepelbagaian yang dicatatkan di kawasan kajian adalah sederhana dan dikategorikan berada dalam persekitaran marin dengan saliniti normal. Spesies paling dominan ialah Asterorotalia pulchella (17.24\%) daripada famili Rotaliidae yang merupakan famili paling dominan $(26.14 \%)$ di kawasan kajian. Spesies sub-dominan di delta Sungai Kelantan ialah Operculina ammonoides dan Amphistegina lessonii. Spesies-spesies yang direkodkan merupakan spesies bagi persekitaran marin berair cetek dan biasa dijumpai di perairan Laut China Selatan. Kedalaman air dan saliniti air mempengaruhi kepelbagaian dan kelimpahan foraminifera di delta Sungai Kelantan.

\section{PENGHARGAAN}

Setinggi-tinggi penghargaan ditujukan kepada UKM atas tajaan geran penyelidikan (Kod Projek: DPP-2015-075 dan INDUSTRI-2013-027) dan juga Pusat Pengajian Sains Sekitaran dan Sumber Alam, Fakulti Sains dan Teknologi, UKM bagi kemudahan SEM yang disediakan.

\section{RUJUKAN}

Annin, V.K. 2001. Benthic foraminifera assemblages as bottom environmental indicators, Posiet Bay, Sea of Japan. Journal of Asian Earth Sciences 20: 9-29.

Asis, J. \& Jasin, B. 2015. Miocene larger benthic foraminifera from the Kalumpang Formation, Tawau, Sabah. Sains Malaysiana 44(10): 1397-1405.

Culver, S.J., Mallinson, D.J., Corbett, D.R., Leorri, E., Rouf, A.A., Shazili, N.A.M., Yaacob, R., Whittaker, J.E., Buzas, M.A. \& Parham, P.R. 2012. Distribution of foraminifera in the Setiu estuary and lagoon, Terengganu, Malaysia. Journal of Foraminiferal Research 42(2): 109-133.

Culver, S.J., Leorri, E., Corbett, D.R., Mallinson, D.J., Shazili, N.A.M., Mohammad, M.N., Parham, P.R. \& Yaacob, R. 2013. Infaunal mangrove swamp foraminifera in the Setiu
Wetland, Terengganu, Malaysia. Journal of Foraminiferal Research 43: 262-279.

Dhillon, D.S. 1969. Three new species of foraminifera from Malaysia. Journal of Paleontology 43(3): 767-770.

Fisher, R.A., Corbert, A.S. \& Williams, C.B. 1943. The relationship between the number of species and the number of individuals in a random sample of an animal population. Journal of Animal Ecology 12: 42-58.

Frezza, V. \& Carboni, M.G. 2009. Distribution of recent foraminiferal assemblages near the Ombrone River mouth (Northern Tyrrhenian Sea, Italy). Revue de Micropaléontologie 52: 43-66.

Haynes, J.R. 1981 . Foraminifera. London: Macmillan Publisher Ltd.

Husain, M.L., Satyanarayana, B. \& Ibrahim, R. 2007. Downcore variations of foraminiferal distribution in the mangrove sediments of Kapar and Matang, West Coast of Peninsular Malaysia. Journal of Sustainability Science and Management 2(2): 38-54.

Hwakes, A.D., Bird, M., Cowie, S., Grundy-Warr, C., Horton, P., Hwai, A.T.S., Law, L., Macgregor, C., Nott, J., Ong, J.E., Rigg, J., Robinson, R., Tan-Mullins, M., Sa, T.T., Yasin, Z. \& Aik, L.W. 2007. Sediments deposited by the 2004 Indian Ocean tsunami along the Malaysia-Thailand Peninsula Quaternary land-ocean interactions; sea-level change, sediments and tsunami. Marine Geology 242: 169-190.

Jones, R.W. 1994. The Challenger Foraminifera. Oxford: Oxford University Press.

Loeblich, A.R. \& Tappan, H.N. 1988. Foraminifera Genera and their Classification. New York: University of Kansas Press.

Mendes, I., Gonzalez, R., Dias, J.M.A., Lobo, F. \& Martins, V. 2004. Factors influencing recentbenthic foraminifera distribution on the Guadiana shelf (southwestern Iberia). Marine Micropaleontology 51: 171-192.

Milker, Y. \& Schmiedl, G. 2012. A taxonomic guide to modern benthic shelf foraminifera of the western Mediterranean Sea. Palaeontologia Electronica 15(2): 1-134.

Minhat, F.I., Yahya, K., Talib, A. \& Ahmad, O. 2014. Benthic foraminiferal distributions as bioindicators in coastal waters of Penang National Park, Malaysia. Journal of Foraminiferal Research 44(2): 143-150.

Mohamed, K.R., Ali, C.A. \& Said, A. 1997. Perubahan dan perkembangan Delta Kelantan. Sains Malaysiana 26(2): 83-101.

Murray, J.W. 1991. Ecology and distribution of benthic foraminifera. Dlm. Biology of Foraminifera, disunting oleh John, J.L. \& Anderson, O.R. London: Academic Press Inc. hlm. 221-252.

Murray, J.W. \& Alve, E. 1999. Natural dissolution of shallow water benthic foraminifera: Taphonomic effects on the palaeoecological record. Palaeogeography, Palaeoclimatology, Palaeoecology 146: 195-209.

Noraswana Nor Faiz, Ramlan Omar, Muhamad Naim Abd Malek, Chuanshun Li \& Yanguang Liu. 2016. Taburan dan kepelbagaian foraminifera bentik di dalam sedimen permukaan sekitar Delta Sungai Pahang, Pahang, Malaysia. Sains Malaysiana 45(5): 669-676.

Pawlowski, J. 2009. Foraminifera. Dlm Encyclopedia of Microbiology (3rd ed.), disunting oleh Schaechter, M. Oxford: Academic Press. hlm. 646-662.

Pringgoprawiro, H. \& Kapid, R. 2000. Foraminifera: Pengenalan Mikrofosil dan Aplikasi Biostratigrafi. Bandung: Penerbit ITB. 
Sen Gupta, B.K. 2003. Modern Foraminifera. Dordrecht: Kluwer Academic Publishers.

Shannon, C. \& Weaver, W. 1949. The Mathematical Theory of Communication. Urbana: University of Illionis Press.

Renema, W., Hoeksema, B.W. \& van Hinte, J.E. 2001. Larger benthic foraminifera and their distribution patterns on the Spermonde shelf, South Sulawesi. Zoologische Verhandelingen 334: 115-149.

Szarek, R., Kuhnt, W., Kawamura, H. \& Kitazato, H. 2006. Distribution of recent benthic foraminifera on the Sunda Shelf (South China Sea). Marine Micropaleontology 61: 171-195.

Troelstra, S.R., Jonkers, H.M. \& de Rijk, S. 1996. Larger benthic foraminifera from the Spermonde Archipelago (Sulawesi, Indonesia). Scripta Geologica 113: 93-120.

Valchev, B. 2003. On The potential of small benthic foraminifera as paleoecological indicators. Recent Advances 46: 189-194.

Whatley, R.C.\& Zhao, Q. 1987. The recent ostracoda of Malacca Straits (Part I). Revista Espanola de Micropaleontologia 19(3): 327-366.

Whittaker, J.E. \& Hodgkinson, R.L. 1979. Foraminifera of the Togopi Formation, Eastern Sabah, Malaysia. London: British Museum.
Yahya, K., Shuib, S., Minhat, F.I., Ahmad, O. \& Talib, A. 2014 The distribution of benthic foraminifera assemblages in the north-west coastal region of Malacca Straits, Malaysia. Journal of Coastal Life Medicine 2(10): 784-790.

Pusat Pengajian Sains Sekitaran dan Sumber Alam

Fakulti Sains dan Teknologi

Universiti Kebangsaan Malaysia

43600 UKM Bangi, Selangor Darul Ehsan

Malaysia

*Pengarang untuk surat-menyurat; email: iswana08@gmail.com

Diserahkan: 28 April 2016

Diterima: 12 September 2017 
PLAT 1

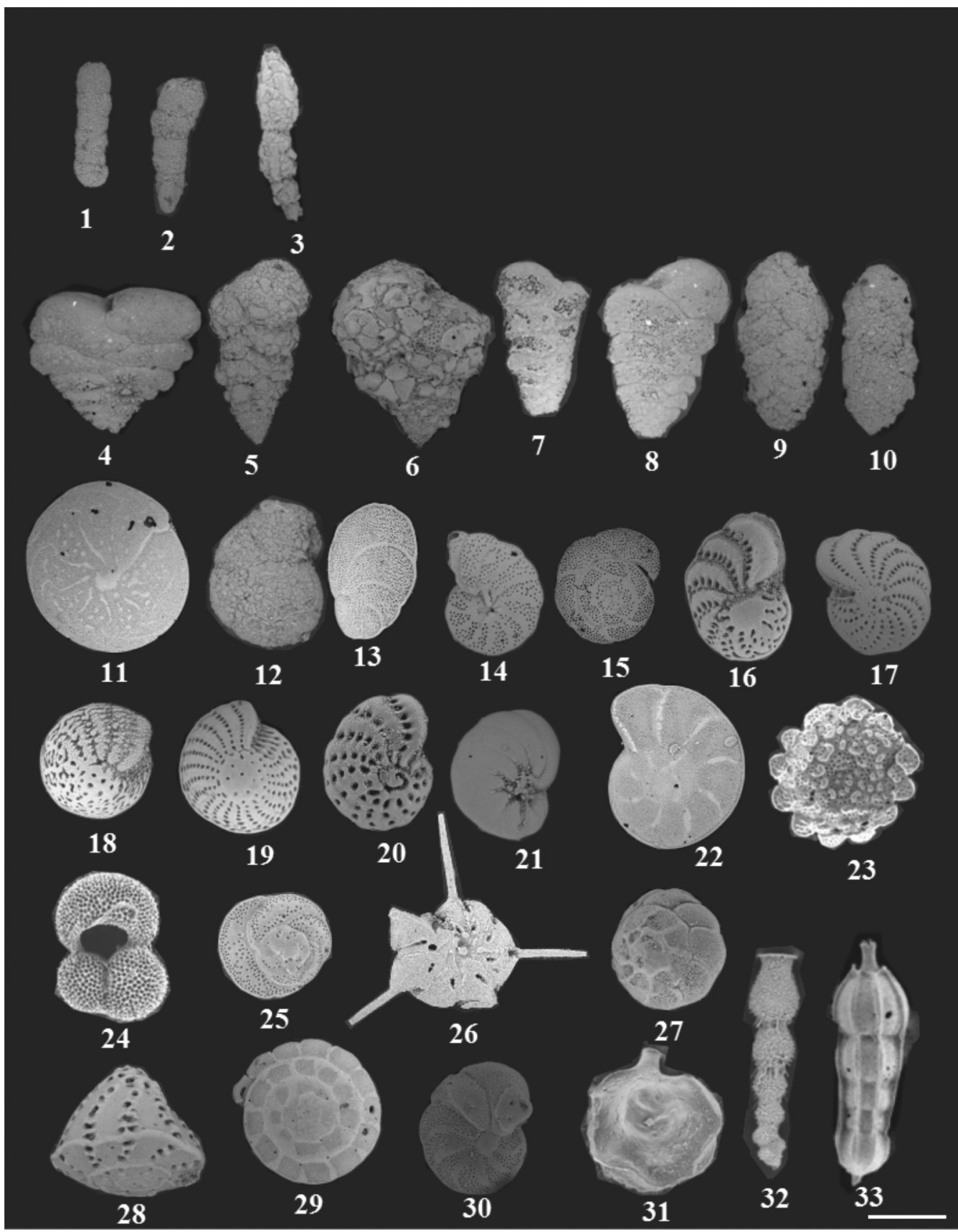

Order Lituolida (skala palang = $200 \mu \mathrm{m}$ ): 1. Ammbaculites agglutinans; 2. Ammobaculites filiformis; 3. Reophax scorpiurus Order Textulariida: 4. Sahulia conica; 5. Textularia agglutinans; 6. Textularia aciculata; 7. Textularia cushmani; 8. Textularia pseudogramen; 9. Textularia sp.; 10. Bigenerina sp. Order Rotaliida: 11. Amphistegina lessonii; 12. Anomalina pacoraensis; 13. Cancris inflatus; 14 Lobatula lobatula; 15. Cibicides dutemplei; 16. Elphidium advenum; 17. Elphidium crispum; 18. Elphidium hispidulum; 19. Elphidium biperforatus; 20. Elphidium sp.; 21. Nonion fabum; 22. Operculina ammonoides; 23. Planorbulinella larvata; 24. Globigerina sp.; 25. Neoconorbina terqeumi; 26. Asterorotalia pulchella; 27. Ammonia tepida; 28. Pseudorotalia schroeteriana; 29. Cavarotalia annectens; 30. Discorbinella sp.; 31. Siphonina sp.; 32. Allassoida virgula; 33. Siphogenerina raphana 
PLAT 2

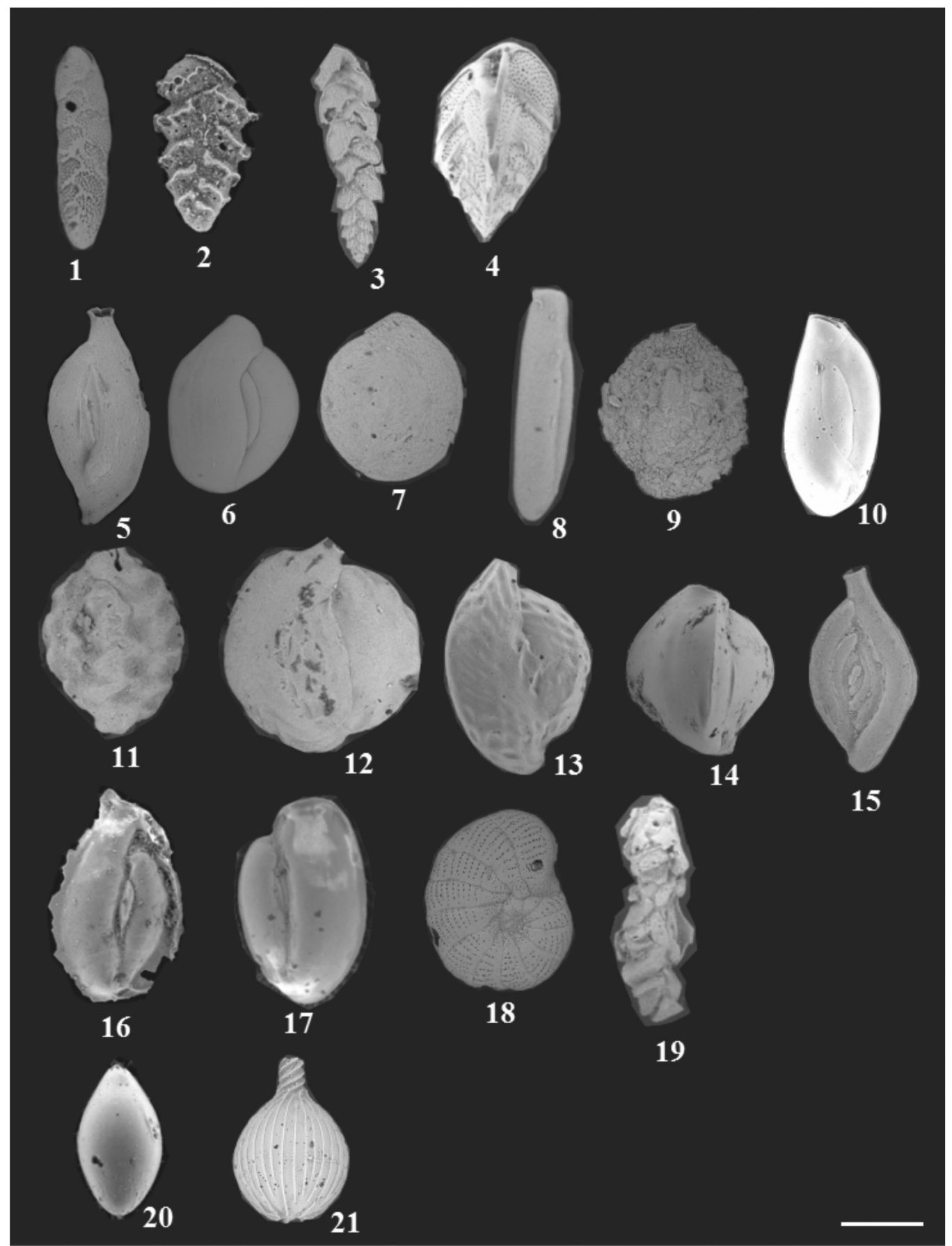

Order Buliminida (skala palang $=200 \mu \mathrm{m}$ ): 1. Brizalina striatula; 2. Pseudobrizalina lobata; 3. Bolivina $\mathrm{sp}$; 4. Reussella spinulosa Order Miliolida: 5 . Adelosina sp 6. Miliolinella australis; 7. Pseudohauerina sp.; 8. Pyrgo millettii; 9. Quinqueloculina agglutinans; 10. Quinqueloculina laevigata; 11. Quinqueloculina parkeri; 12. Quinqueloculina philippinensis; 13. Quinqueloculina reticulata; 14. Triloculina tricarinata; 15. Spiroloculina communis; 16. Edentostomina cultrata; 17. Edentostomina sp.; 18. Peneroplis pertusus; 19. Nubeculina sp. Order Lagenida: 20. Oolina globosa; 21. Lagena striata 